\title{
A survey of needle sticks and other sharp injuries among dental undergraduate students
}

\author{
Mohamed Abdullah Jaber \\ College of Dentistry, Ajman University of Science \& Technology.
}

doi: 10.3396/ijic.V7i3.022.11

\begin{abstract}
Health-care workers (HCWs) including dental students are at occupational risk of exposure to blood-borne viruses (BBV) following needle sticks and sharp injuries (NSIs). The purpose of this study was to determine the prevalence of NSIs among dental students and evaluate the circumstances in acquiring such injuries. A survey was carried out of all clinical dental students in the College of Dentistry, Ajman University of Science and Technology, United Arab Emirate (UAE) by means of an anonymous self-administered questionnaire that asked questions on demography, number, type, level of knowledge of inoculation injuries and associated risks of exposure to BBV, management and reporting of such exposures. Of 230 dental students that responded to the questionnaire (response rate of 92 percent), 64 (27.9\%) were males and $166(72.1 \%)$ were females, 132 $(57.3 \%)$ were $4^{\text {th }}$ year students and $98(42.7 \%)$ from $5^{\text {th }}$ year students.

Of the total sample, 53 students reported having had an inoculation injury, resulting in a 0.23 sharp injury events per student per year. Recapping a needle, administering local anesthesia and performing scaling and polishing procedures were the most important causes of NSIs among dental students $(60.3 \%, 32 / 53)$. Despite a comprehensive educational programme and training for dental students, knowledge of inoculation injuries and associated issues remained inadequate. The findings of this study confirm that dental students experience NSIs but are not likely to report them, thus it is important that the principles of infection control training and reporting of all NSIs continue to be emphasized throughout undergraduate dental education.
\end{abstract}

Key words

Dental students; Blood-borne viruses; Needle stick injuries; Sharps injuries

\author{
Corresponding author \\ Dr Mohamed A Jaber \\ Associate Professor/ Department of Surgical Sciences \\ College of Dentistry, Ajman University of Science \& Technology. \\ Ajman, P O Box 346, United Arab Emirates \\ Telephone: (+971) 067482222 Mobile: (+971) 0505178052 \\ Fax: (+971) 067056462 \\ Email: mjaber4@hotmail.com
}




\section{Introduction}

Health care workers (HCWs) are at risk of exposure to a variety of blood-borne pathogens by needle stick and sharp injuries or mucocutaneous contamination. ${ }^{1,2}$ Blood-born viruses (BBVs) in particular hepatitis B (HBV), hepatitis $\mathrm{C}(\mathrm{HCV})$, and HIV can be transmitted occupationally from infected staff to patients, from infected patients to staff, or from patient to patient via contaminated instruments. The most common route of transmission is from patients with a BBV to a member of staff following a needle sticks and sharp injuries (NSIs) or splash exposure of the mucous membranes. Since the 1980s, there has been an increase in the reported incidence of blood-borne infections amongst HCWs and a concomitant enhanced awareness of the occupational risks of BBV transmission.]

Overall incidence rates for NSIs in dental schools have ranged from 1.97/10,000 visits $^{4}$ to $12.5 / 10,000$ visits. ${ }^{5}$ Some of these analyses include only faculty and staff, whereas others include students and residents. Younai et al. observed a considerably higher rate of injury for third-year students compared to fourth-year, ${ }^{4}$ suggesting an elevated risk in the third year due to inexperience in performing invasive procedures. In an observational study of dental residents, the majority of NSIs occurred extra-orally during removable prosthetic procedures. $^{5}$

Although the likelihood of being infected by a BBV may be low after a single exposure, the consequences for the Dental student who becomes infected are potentially serious, and include the potential of transmission of blood-borne pathogens and associated detrimental effects on their personal and professional lives. Indeed, the UK Dept. of Health guidelines recommend that hepatitis $\mathrm{C}$ positive HCWs including dental students may not be permitted to embark upon careers that include exposure-prone procedures. ${ }^{7}$

Dental students' knowledge of correct procedures, which reduce the risk of sharps injuries thus decreasing the likelihood of contracting blood-borne viruses, must be evaluated regularly in order to identify any need for further education. This is especially important as there is currently no post-exposure prophylaxis for hepatitis $\mathrm{C}$, and hepatitis B immunization may not completely protective in certain individuals. Non- response to hepatitis $B$ vaccination is seen in only a small proportion of individuals vaccinated with an adequate schedule and has a strong genetic basis. ${ }^{8}$ Furthermore, non-responders have a lower cytokine response to the vaccine than responders. ${ }^{9}$ However, the rate of low or non-response is much higher in patients with uremia up to $30 \%$ failing to respond to the usual vaccination schedules. Co-infection with hepatitis $C$ seems to further lower the response rate in such patients. ${ }^{10}$ In addition, genetic determinants are also present in uremic patients. ${ }^{11,12}$

Despite the risk of NSIs, several studies have highlighted that knowledge and compliance among dental students is inadequate regarding their prevention and management. ${ }^{13,14}$ Dental students are particularly vulnerable to accidental exposure to potentially infected body fluids because they lack experience and skill in carrying out dental procedures. ${ }^{15}$ However, the exact risk of exposure to BBVs among dental students is unknown.

Despite the growing body of knowledge concerning NSIs among practicing dentists, there has been little research focusing on needle sticks in the student population in the United Arab Emirate (UAE), thus the purpose of this survey was to determine the prevalence of NSIs among the clinical dental students, reporting practices, management of exposure incidents and evaluate the circumstances around this situation.

\section{Methods}

The survey was carried out using questionnaire-based methodology. The pre-tested anonymous two-page questionnaire consisted of closed and open ended questions divided into twenty-six questions. The questionnaire used a simple tick-box format, with sections for demographic items (such as age, sex and year of study), frequency of sharp injuries, including number and nature, and reporting practices, type of device that caused the injury, the event that lead to the NSIs, and whether the event was reported. We also asked about reasons for non-reporting and the total number of NSIs events. Knowledge variables included the knowledge of the NSIs, Sharp injuries guidelines, policies and protocols and their relevant experience of managing these injuries. Students were questioned on their HBV immunization status, post exposure 
management. A 12-month recall period was used throughout the questionnaire. The survey instrument was distributed and collected during April 2007 at the end of a lecture or practical session for each of the 4 years and $5^{\text {th }}$ year of the programme following a verbal briefing of the students by investigators. For the purposes of this study, NSIs was defined as any needle stick injury or cut; or a blood or body fluid splash to eyes, nose or mouth or broken skin. There were no penalties or rewards for participation, and students were told that participation was voluntary. Informed consent was implied when students completed and returned their questionnaires.

The College of Dentistry publishes and widely distributes comprehensive guidelines encompassing practical procedures aimed at prevention of sharps injuries. The guidelines advise that general precautions are taken for any procedure that could involve contact with blood or other body fluids. They also clearly state that specialist training exposure-prone procedures must be received before undertaking any procedure involving sharp devices on patients. During clinical stage of their study additional training on NSIs and prevention is also undertaken. In addition, to the infection control course they took during the second year.

Two hundred and fifty dental students at the College of Dentistry, Ajman University of Science and Technology, UAE participated in this survey. This included 100 final year students and 150 fourth year students. Attached to each questionnaire was a covering letter explaining the purpose of this study and reassuring students of their anonymity.

Ethical approval for the study was obtained from the Ethics Committee for Research of the College of Dentistry, Ajman University, UAE.

\section{Statistical analysis}

Data were anonymously coded and entered into statistical software (SPSS software version 12.0) for analysis. Basic statistics were calculated, including prevalence rates and overall numbers of NSI. NSIs events were calculated as a percentage of all students and also as a proportion of all cases. Differences in NSI prevalence by students' year of study were investigated using the chi-square test and the results were considered significant when $p<0.05$.

Table I. Demographics of 230 responding students

Factors

\section{Gender}

Male

Female

Academic year

$4^{\text {th }}$ year

\section{Hepatitis B Vaccination status}

Full vaccination

Incomplete vaccination

Not vaccinated

\section{Attendance at meetings (at least once during the last year)}

Ministry of health organized (MOH) 


\section{Results}

By the end of April 2007, two hundred and thirty completed questionnaires (response rate 92\%) had been returned. The present report details the responses of this cohort of responding dental students.

Of the 230 dental students responded to the questionnaire, 64 (27.9\%) were males and $166(72.1 \%)$ were females with a mean age of 20 years. Among the different categories of responding dental students, 132 $(57.3 \%)$ were $4^{\text {th }}$ year students, $98(42.7 \%)$ from $5^{\text {th }}$ year students. The majority of the students 96\% (221/230) were started their immunization against hepatitis B, but $89 \%$ percent $(198 / 221)$ of the immunized students knew their actual level of immunity. Of note however, $4.0 \%(9 / 230)$ of dental students were not immunized against HBV (Table I).

A total of 53 students (23\%) reported a NSIs during the previous 12 months, thirty five of whom were final year students and 18 were fourth year student resulting in a $0.23 \mathrm{NSIs}$ events per student per year.

Among dental students, most injuries involved a syringe needle followed by scaler and other dental instruments such as bur, explorer, scalpel, a suture needle and other devices. Recapping a needle and administering local anesthesia, and performing scaling and polishing procedures were the most important causes of NSIs among dental students (32/53 60.3\%). The other procedures that resulted in the exposure incidents are shown in Figure 1.

The students were asked whether or not they considered bites, splashes into mucous membranes, or needle stick inoculation via the skin to be sharps injuries. Only 67 of 230 students (29.1\%) correctly defined a sharps injury; these were 25 fourth year students and 42 final year students. Forty-nine percent (113/230) of students were aware that a bite constituted a sharps injury. Other types of sharps injury were, however, poorly understood. For example, only 50.4\% (116/230) considered a scratch to be sharps injury. Similarly, only $87.3 \%$ considered a blade, $50.8 \%$ a scissors, $50.4 \%$ a scratches and $32 \%$ a splash of body fluid into mucous membranes to be a sharps injury. In addition, 28.2\% (65/230) of students incorrectly considered that a stab with a clean needle constituted NSIs (Table II).

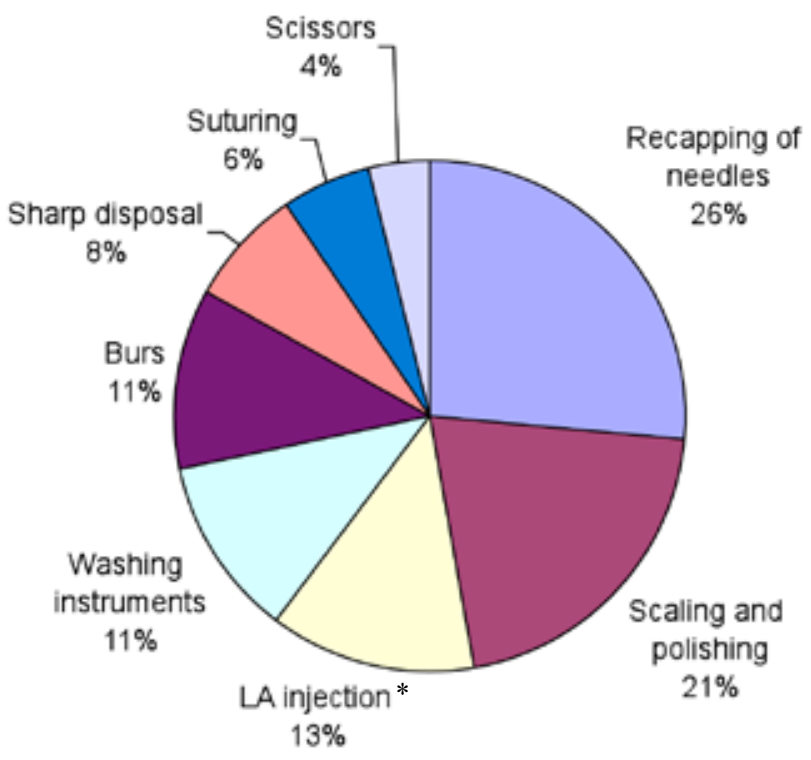

*LA = Local Anaesthesia

\section{Figure 1: Distribution of procedures causing the precutaneous injuries}

Overall, final year dental students were significantly more knowledgeable regarding sharps injuries than fourth year students $\left(p<0.0001, X^{2}=29.1\right)$. Fortyseven percent (108/230) of students considered that it was acceptable practice to recap needles. Significantly more fourth year students $(62.8 \%, 83 / 132)$ than final year students $(25.5 \%, 25 / 98)$ said that they would recap needles $\left(p=0.03, X^{2}=4.69\right)$.

Among those who had NSIs, only 39.6\% (21/53) had reported the incident, as illustrated in Table II. The most common reasons for failure to report the incidents of $\mathrm{NSI}$, as declared by most of the participants, included fear of stigmatization and discrimination and fear of the consequences of such injuries. Other causes of none reporting of NSI incidents were detailed in Table III.

Forty-two percent (97/230) of students correctly identified the appropriate staff to notify following a NSI incidents during working hours. This included $34.9 \%$ of fourth year students and $52.0 \%$ of final year students. Only 47.8 percent (110/230) of students were aware of existence of protocol for post-exposure management and fifty-four percent (125/230) of students reported having knowledge of first aid measure to manage NSIs (Table IV). 
Table II. Knowledge of dental students on sharp injuries

\begin{tabular}{|c|c|c|c|c|c|}
\hline \multirow[t]{2}{*}{ Knowledge items } & \multirow{2}{*}{$\begin{array}{r}\text { Response } \\
\text { given }\end{array}$} & \multicolumn{2}{|c|}{ No of students } & \multirow{2}{*}{$\begin{array}{r}\text { Total } \\
\text { No }(\%)\end{array}$} & \multirow{2}{*}{$\begin{array}{r}\text { Chi-square } \\
\text { and } \\
P \text { value }\end{array}$} \\
\hline & & 4th year & 5th year & & \\
\hline \multirow[t]{3}{*}{ Do you ever have NSI? } & Yes & 18 & 35 & $53(23.0)$ & $P<0.001$ \\
\hline & No & 108 & 62 & $170(74.0)$ & \\
\hline & Don't know & 6 & 1 & $7(3.0)$ & \\
\hline \multirow{2}{*}{$\begin{array}{l}\text { Have you reported the } \\
\text { incident of NSI }\end{array}$} & Yes & 8 & 13 & $21(40.0)$ & $P=0.04$ \\
\hline & No & 21 & 11 & $32(60.0)$ & \\
\hline \multirow{2}{*}{$\begin{array}{l}\text { Should needle be } \\
\text { recapped after use }\end{array}$} & Yes & 83 & 25 & $108(47.0)$ & $P=0.03$ \\
\hline & No & 107 & 15 & $122(53.0)$ & \\
\hline \multirow{2}{*}{$\begin{array}{l}\text { Do you know about the } \\
\text { universal precaution } \\
\text { guidelines? }\end{array}$} & Yes & 120 & 92 & $212(92.1)$ & NS \\
\hline & No & 12 & 6 & $18(7.9)$ & \\
\hline \multirow{2}{*}{$\begin{array}{l}\text { Do you know about } \\
\text { needle less safety devices? }\end{array}$} & Yes & 125 & 90 & $215(93.5)$ & NS \\
\hline & No & 7 & 8 & $15(6.5)$ & \\
\hline
\end{tabular}

Do you consider the

following to be sharp

injuries?

Bites

Splashes into mucous

47

21

66

$113(49.1)$

$P<0.001$

membrane

Needle stick via skin

Scratches

Scalpel injuries

Scissors injuries

Elevators injuries

Stab with clean needle

Sharp injury definition

Correct definition

Incorrect definition
25

107

$\begin{array}{rrr}132 & 98 & 230(100.0) \\ 48 & 68 & 116(50.4) \\ 103 & 98 & 201(87.3) \\ 55 & 62 & 117(50.8) \\ 43 & 58 & 101(44.0) \\ 22 & 43 & 65(28.2)\end{array}$

73 (32.0)

67 (29.1)

$P<0.001$ 
Table III. Reason for non-reporting of NSI by the dental students

\begin{tabular}{lcccr} 
Reasons & \multicolumn{2}{c}{$\mathbf{4}^{\text {th }}$ year students } & \multicolumn{2}{c}{$\mathbf{5}^{\text {th }}$ year students } \\
& $\mathbf{N o}$ & $\mathbf{\%}^{*}$ & $\mathbf{N o}$ & $\mathbf{\%}^{*}$ \\
\hline Fear of stigmatization and discrimination & 8 & 25.0 & 4 & 12.5 \\
\hline The item was unused & 6 & 18.7 & 3 & 9.3 \\
\hline I didn't know how to report it & 4 & 12.5 & 1 & 3.1 \\
\hline It was only minor, so I didn't worry & 2 & 6.2 & 2 & 6.2 \\
\hline I was too embarrassed to report it & 1 & 3.1 & 1 & 3.1 \\
\hline
\end{tabular}

$* \%$ out of 32 students declared non-reporting of the NSI incident

Table IV. Effect of academic year on student's knowledge and practices related to management of NSIs

\begin{tabular}{lccc} 
& $\begin{array}{r}\mathbf{4}^{\text {th }} \text { year students } \\
(\mathbf{n = 1 3 2})\end{array}$ & $\begin{array}{c}\mathbf{5}^{\text {th }} \text { year students } \\
(\mathbf{n = 9 8 )}\end{array}$ \\
\hline $\begin{array}{l}\text { Reporting of NSIs } \\
\text { Knowledge of availability of } \\
\text { professional staff to report to }\end{array}$ & $\mathbf{8}$ & 13 & 0.275 \\
\hline $\begin{array}{l}\text { Awareness of any guideline } \\
\text { or protocol for post-exposure } \\
\text { management in the college }\end{array}$ & 38 & 51 & 0.612 \\
\hline $\begin{array}{l}\text { Knowledge of first aids measure } \\
\text { to manage NSIs }\end{array}$ & 50 & & \\
\hline
\end{tabular}

$P=0.37$

\section{Discussion}

Dental students like other health care workers face a recognized risk of occupational exposure to BBV such as the Human Immunodeficiency Virus (HIV), the hepatitis $B$ virus (HBV), and the hepatitis $C$ virus (HCV). ${ }^{16,17}$ Although the survey was conducted in the first accredited dental college in UAE, the results may not be generalized to all UAE dental colleges because of the differences in the training programmes and clinical requirements. The excellent response rate achieved illustrates the value of mass administration of short questionnaires following a brief verbal introduction. One possible limitation of questionnairebased studies is that what people report may differ 
from what they actually do and the findings may be underestimated since it relied on the respondent memory which might give a chance for the occurrence of recall bias.

Although blood contacts with skin and mucous membranes may be reduced through use of traditional barriers, such as gloves which reduces the inoculum of blood when the needle pass through glove, these barriers are not effective in preventing injuries with sharp instruments. When a student is exposed to NSIs, the risk of transmitting various types of blood-borne pathogens from an infected patient is greatly increased.

The occurrence of NSIs in this study compared favorably with that in other reports in term of incidence and circumstances around needlestick injuries. ${ }^{18,19}$ The high prevalence of sharp injuries among dental students should be of concern because such injuries can lead to serious consequences. Other studies of medical students around the world also seem to support the high prevalence of sharp injuries among medical and dental students. NSIs among medical students has been reported internationally at the following rates: $24 \%$ in France, ${ }^{20} 30-33 \%$ in the United States of America (USA), ${ }^{21,22} 12-33 \%$ in England ${ }^{23}$ and $35 \%$ in Singapore. ${ }^{24}$ Of the 53 students who reported NSIs during our investigation, (approximately 0.23 NSI events per student per year), 60.3\% (32/53) were $4^{\text {th }}$ year students and $39.7 \%(21 / 53)$ were $5^{\text {th }}$ year students. Injuries in a dental college come from many causes. Some are related, directly or indirectly, to patient treatment. Others occur during preclinical laboratory exercises or in a dental laboratory. Drexler et al. ${ }^{25}$ reported that one half of all medical students and nursing students have experienced an exposure to blood or body fluids during the final two years of study. One study reported that only five out of twelve nursing students exposed to biologically hazardous material reported the incident. This study also found that students exposed to NSIs experience fear of contracting potential infections such as HIV/AIDS, Hepatitis B and C. They also experienced feelings of fear of contracting infections such as HIV/AIDS, Hepatitis B and C, insecurity of loosing their carrier, and low self esteem as a consequence of getting the infection. ${ }^{26}$ The emotional impact of an NSIs can be severe and long lasting, even if a serious infection is not occurred. It is not known why the infection status of the source patient can accentuate the injured individual's stress.

Much concern has been expressed in the literature about the underreporting of injuries occurring in the dental teaching environment. ${ }^{4,27}$ It is unlikely that the data presented in the current study represent 100 percent of all the incidents that occurred in our dental college. Judging from the low reported injury rate for students in the current study there might be some reluctance among students to strictly comply with the written guidelines of college with regard to the reporting of injuries. Low compliance among students, especially in reporting of injuries, may be partly explained by the perception that they are insignificant and pose no risk to them and this may be due dental students doing their own risk assessment. Other reason, could be the heavy clinical schedule and students more concerned with finishing of their clinical requirement. However, when the potential for blood or body fluid contact exists, the risk of exposure to blood- borne pathogen is high. The importance of properly reporting all NSIs to the proper authorities must first be promoted throughout the faculty of each institution before it can be expected to be appreciated by the student and staff. For example, it has being reported that only half of faculty who experienced occupational exposures reported a problem to someone in the Occupational Health Department. ${ }^{4}$ Smoot reported that "most students indicate that they do not see routine universal precautions undertaken by staff and residents, and no requirement for the compliance is enforced" ${ }^{28}$

Around $60 \%$ of NSIs were not reported by dental students. Non-reporting of NSIs is a contentious issue within the dental profession the most common reason for that was the student's lack of knowledge that all injuries had to be reported. Aiken et al. ${ }^{29}$ reported that NSIs are more common than institutional figures suggest and do not occur at random. Shiao et al. ${ }^{30}$ conducted a detailed epidemiological study and showed that $81 \cdot 8 \%$ of NSIs were not reported by Taiwanese health care workers. Previous investigation of British medical students $^{23}$ also showed that $75 \%$ did not report their NSIs. Similar to our study, the medical students' reasons for non-reporting included low perceived risk and embarrassment. Our results clearly suggest that the 
reporting of NSIs needs to be reinforced among dental students. Increased reporting rates may be achieved through enhanced education, particularly for younger students who may not yet be aware of official reporting processes or the consequences of contaminated sharp injuries when they enter university or a teaching hospital. This is especially true in developing countries which often focus on the provision of clinical care and treatment facilities at the workplace with less emphasis on preventive services. This may be related to the perceived value of the clinical skills of the doctor and nurse available at the workplace, plus the lack of other occupational health personnel, and the limited access to occupational hygiene and laboratory facilities.

Recapping and using the local anesthetic syringe and scaling were the two most important causes of NSIs among dental students. Studies indicated syringe use as the major cause of NSIs among dental professionals. ${ }^{31-33}$ In dental practice, multiple injections are usually given over the course of the patient's treatment. These activities place dental professionals at an increased risk of sustaining needle stick injuries. Recapping has been identified as a habitual behavior, based on the desire to remove a sharp, and potentially dangerous object, from the immediate environment. In this study, $66 \%$ of dental students indicated they would recap needles in an apparent attempt to perform safe practice and decrease the risk of inoculation injury. The literature consistently shows that it is during the process of recapping and disposing of the needles that most needlecaused sharps injuries occur. Improved knowledge and training can reduce NSIs significantly. ${ }^{34,35}$ The one handed 'scoop' technique for recapping has been promoted widely and there is evidence that it is highly effective, even for non-experience users. ${ }^{36,37}$

The risk factors involved in NSIs have been extensively studied. Aiken et al. ${ }^{29}$ suggested that many of the NSIs occur during needle recapping which is in agreement with the findings of the current study. Another study focused on working conditions, shortage of staff, and the influence on increases in accidental injuries. ${ }^{38}$

Vaccination rates compared favorably with those seen in other studies (percent of vaccination). Previous investigation of NSIs among Australian medical and dental students showed their hepatitis B vaccination rates to be $98 \%$ and $95 \%$, respectively. ${ }^{39}$ Such a result would particularly desirable, as hepatitis $B$ is one of the major infectious disease threats for health care workers. However, a substantial number of students (16.5 percent) did not complete the three-dose vaccination course. The exact reason for non-completion is unknown, one possible reason is that this survey was carried out in the first semester of the $4^{\text {th }}$ year, the year in which the students start their clinical training, some of the students may have only completed their first dose and are awaiting to complete the full vaccination regimen later. Furthermore, $4 \%$ of $4^{\text {th }}$ year students were not vaccinated against HBV. This could be due to lack of strict monitoring of the vaccination status prior to commencing of the clinical work. This is a serious shortcoming and stresses the need for closer monitoring and enforcement of immunization protocol amongst dental students. Unvaccinated individuals may have a $6-30 \%$ risk of becoming infected with the virus following an injury. ${ }^{40}$

A study from the UK quoted the risk associated with transmission of HBV to a non-immune health care worker to range from $2 \%$ if the source patient is Hepatitis Be antigen negative to $40 \%$ if the patient is Hepatitis Be antigen positive. ${ }^{41}$ Prospective studies of health care workers exposed to HCV through a needlestick or other NSIs have found that the incidence of anti-HCV sero-conversion averages $1.8 \%$ (range $0 \%$ $7 \%$ ) per injury. ${ }^{42}$ One study reported that transmission occurred only from hollow-bore needles as compared with other sharp objects as they carry more blood. ${ }^{43}$ A data combined from more than 20 prospective studies worldwide of health care workers exposed to HIV infected blood through NSI revealed an average transmission rate of $0.3 \%$ per injury. ${ }^{44}$ The findings of this study have shown that among the 53 students with a history of NSIs, $32(40 \%)$ never reported the incident to a doctor to get post-exposure treatment because they were not aware of the importance of post-exposure prophylaxis.

Attempts at reducing the number of NSIs have included the development of various safety devices and the implementation of special techniques. ${ }^{45,46}$ However, the introduction of safety needles in the dental environment has not necessarily proven to be safer than traditional anesthetic needles. ${ }^{45}$ Because it is difficult to evaluate the 
efficacy of dental safety needles. Since needlestick injuries are relatively rare, it would require a prohibitively large sample size to proof statistically that a device significantly decreases the incidence of needlestick injuries. It seem the problem is not a lack of safety devices but failure to use these devices. ${ }^{47}$ Students are instructed as to the proper technique of uncapping and recapping the needle. This technique must be reinforced by each faculty instructor during the clinical sessions. It is evident, however, that despite continuous education, there are still some dental students with gaps in their knowledge which puts them at risk. This needs to be considered by the dental college. Perhaps in addition to education, there is a need to introduced needle stick protection devices to offer protection to this vulnerable group.

The results of this study revealed that post-exposure management was completely inadequate especially the reporting of occupational exposures. The majority of the students failed to report the exposure incidents. Although studies have observed that reporting of occupational exposures in most centers isgenerally low. Reasons given by the students in this study centered on fear of stigmatization and discrimination. However, post-exposure management protocols exist in all clinics, but the implementation of the protocol appears to be suboptimal given the students' lack of awareness of these procedures. It is important that such protocol and post-exposure incident services be introduced to students at the time of their orientation before they begin their clinic experiences. Access to such programmes should be readily available and rapid so that the time between exposure and post-exposure prophylaxis is as short as possible

The prevention of NSIs remains a key in minimizing the risk transmission of blood-borne viral infections. To that end, there is a need to invest resources into educating students on the proper use of devices, focusing on administration of local anesthetic, recapping, changing the anesthetic carpule and cleaning of instruments, as these factors contributed to a significant proportion of injuries among dental professionals in this study. These measures, if reinforced in dental school, will have a greater chance of being followed once the individual moves into private practice.

The results of this study indicates that dental students in UAE have some knowledge of NSIs; nevertheless they failed to recognize appropriate management and reporting of such injuries, therefore, there is a need for improvements in the clinical training, in particular more instructional time devoted to prevention and management of NSIs. In addition, to education, competence based training should be considered. They should also be made aware of the current procedure and protocol and need support and counseling by their Occupational Health Department. It is the responsibility of academic institutions to facilitate appropriate preclinical immunization and provide training in infection prevention and control to protect patients, health care workers and careers of undergraduates, and to lay the foundation for patients safety and safety of health care workers by promoting safer working practices in health care setting.

\section{References}

1. Davanzo E, Frasson C, Morandin M, Trevisan A. Occupational blood and body fluid exposure of university health care workers. Am I Infect Control 2008; 36(10): 753-756. http. dx.doi.org/10.1016/j.ajic.2008.04.254

2. Deisenhammer S, Radon K, Nowak D, Reichert J. Needlestick injuries during medical training. J Hosp Infect 2006; 63: 263267. http.dx.doi.org/10.1016/j.jhin.2006.01.019

3. May D, Brewer S. Sharps injury: prevention and management. Nursing Stand 2001; 15: 45-52.

4. Younai FS, Murphy DC, Kotelchuck D. Occupational exposures to blood in a dental teaching environment: results of a ten-year surveillance study. J Dent Educ 2001; 65: 436-448.

5. Cleveland JL, Lockwood SA, Gooch BF, et al. Percutaneous injuries in dentistry: an observational study. J Am Dent Assoc 1995; 126(6): 745-751.

6. Trim JC, Elliott TS. A review of sharps injuries and preventative strategies. J Hosp Infect 2003; 53: 237-242. http.dx.doi. org/10.1053/jhin.2002.1378

7. Department of Health, Guidance for Clinical Healthcare Workers: protection against infection with blood-borne viruses. Recommendations for the Expert Advisory Group on AIDS and the Advisory Group on Hepatitis, Department of Health, London (1998).

8. Höhler T, Reuss E, Evers N. Differential genetic determination of immune responsiveness to hepatitis B surface antigen and to hepatitis A virus: A vaccination study in twins. Lancet 2002; 360: 991-995. http.dx.doi.org/10.1016/S01406736(02)11083-X

9. Yamashiki M, Kosaka Y, Kondo I, Nomoto M. Impaired cytokine production by peripheral T lymphocytes in low responders to hepatitis B vaccination. Clin Sci 1997; 92(5): 527-528.

10. Navarro JF, Teruel JL, Mateos ML, Ortuño J. Antibody level after hepatitis B vaccination in hemodialysis patients: Influence of hepatitis C virus infection. Am J Nephrol 1996; 16: 95-97. http.dx.doi.org/10.1159/000168977

11. Pol S, Legendre C, Mattlinger B, Berthelot P, Kreis H. Genetic basis of nonresponse to hepatitis $B$ vaccine in hemodialyzed patients. J Hepatol 1990; 11: 385-387. http.dx.doi. org/10.1016/0168-8278(90)90226-H 
12. Stachowski J, Kramer J, Füst G, Maciejewski J, Baldamus CA, Petrányi GG. Relationship between the reactivity to hepatitis $B$ virus vaccination and the frequency of MHC class I, II and III alleles in haemodialysis patients. Scand I Immunol 1995; 42: 60-66. http.dx.doi.org/10.1111/j.1365-3083.1995. tb03626.x

13. Samaranayake LP, Lamey PJ, MacFarlane TW, Glass DW. Attitude of General Dental Practitioners towards the hepatitis B vaccine. Community Dent Oral Epidemiol 1987; 15: 125-127. http.dx.doi.org/10.1111/j.1600-0528.1987.tb00498.x

14. Porter KM, Scully C, Porter SR. Needle stick injuries in dental staff. Br Dent J 1989; 167: 265-266. http.dx.doi. org/10.1038/sj.bdj.4806995

15. Hauman $\mathrm{CHJ}$. Cross-infection risks associated with highspeed dental handpieces. I Dent Assoc S Afr 1993; 48(7): 389-391.

16. SmithAJ, CameronSO, BaggJ, Kennedy D. Occupational health: Management of needlestick injuries in general dental practice. Br Dent J 2001; 190: 645-650.

17. Siew C, Chang SB, Gruninger SE, Verrusio AC, Neidle EA. Selfreported percutaneous injuries in dentists: implications for $\mathrm{HBV}$, HIV transmission risk. J Am Dent Assoc 1992; 123: 37-44.

18. Callan RS, Caughman F, Budd ML. Injury reports in a Dental school: A two-year overview. J Dent Educ 2006; 70(10): 1089-1097.

19. Elder A, Paterson C. Sharps injuries in UK health care: a review of injury rates, viral transmission and potential efficacy of safety devices. Occup Med (Lond) 2006; 56(8): 566574. http.dx.doi.org/10.1093/occmed/kql122

20. Rosenthal E, Pradier C, Keita-Perse O, Altare J, Dellamonica P, Cassuto JP. Needlestick injuries among French medical students. J Am Med Assoc 1999; 281: 1660. http.dx.doi.org/10.1001/jama.281.17.1660

21. Shen C, Jagger J, Pearson RD. Risk of needle stick and sharp object injuries among medical students. Am J Infec Control 1999; 274: 35-37.

22. Patterson JMM, Novak CB, Mackinnon SE, Ellis RA. Needlestick injuries among medical students. Am J Infec Control 2003; 31: 226-230. http.dx.doi.org/10.1067/ mic. 2003.44

23. Waterman J, Jankowski R, Madan I. Under-reporting of needlestick injuries by medical students. J Hosp Infec 1994; 26:149-150. http.dx.doi.org/10.1016/01956701(94)90058-2

24. Chia HP, Koh D, Jeyaratnam J. A study of needle stick injuries among medical undergraduates. Ann Acade Med (Singapore) 1993; 22: 338-341.

25. Drexler H, Schmid K, Schwager C. Needlestick injuries and other occupations exposures to body fluids amongst employees and medical students of a German university: Incidence and follow-up. J Hosp Infec 2007; 67: 124-130.

26. Elucir Gir, RK, Canini SRM. Accidents with biological material among undergraduate nursing students in a public Brazilian university. The $\mathrm{Br} /$ Infec Dis 2004; 8(1): 18-24. http.dx.doi.org/10.1590/S1413-86702004000100003

27. Kotelchuck D, Murphy D, Younai F. Impact of underreporting on the management of occupational bloodborne exposures in a dental teaching environment. J Dent Educ 2004; 68: 614-622.

28. Smoot EC. Practical precautions for avoiding sharp injuries and blood exposure. Plast Reconstr Surg 1998; 101: 528-534. http.dx.doi.org/10.1097/00006534-199802000-00045

29. Aiken LH, Sloane DM, Klocinski JL. Hospital nurses' occupational exposure to blood: prospective, retrospective, and institutional reports. Am J Public Health 1997; 87: 103-107. http.dx.doi.org/10.2105/ AJPH.87.1.103
30. Shiao JSC, McLaws ML, Huang KY, Ko WC, Guo YL. Prevalence of nonreporting behavior of sharps injuries in Taiwanese health care workers. Am J Infec Control 1999; 27: 254-257. http.dx.doi.org/10.1053/ic.1999. v27.a97006

31. Cleveland JL, Barker L, Gooch BF, Beltrami EM, Cardo D: Use of HIV postexposure prophylaxis by dental health care personnel: an overview and updated recommendations. I Am Dent Assoc 2002, 133(12): 1619-1626.

32. Sullivan $M$, Masters $O$, Venkatesan P. Needlestick injuries amongst medical students in Birmingham, UK. / Hosp Infect 2000; 44: 240-241. http.dx.doi.org/10.1053/ jhin.1999.0697

33. Trim JC, Adams D, Elliott TS. Healthcare workers' knowledge of inoculation injuries and glove use. Br J Nursing 2003; 12: 215-221.

34. Mendelson MH, Lin-Chen BY, Solomon R, Bailey E, Kogan G, Goldbold J. Evaluation of a safety resheathable winged steel needle for prevention of percutaneous injuries associated with intravascular-access procedures among healthcare workers. Infect Control Hosp Epidemiol 2003; 24: 105-112. http.dx.doi.org/10.1086/502174

35. Elliott SKF, Keeton A, Holt A. Medical students' knowledge of sharps injuries. J Hosp Infect 2005; 60: 374-377. http.dx.doi.org/10.1016/j.jhin.2005.01.033

36. Wright GD, Farrer JA. Needle covers reduce needlestick injury. Accid Anal Prev 1993; 25: 153-199. http.dx.doi. org/10.1016/0001-4575(93)90055-2

37. Froom P, Kristal-Boneh E, Melamed S, Shalom A, Ribak J. Prevention of needle-stick injury by the scooping-resheathing method. Am / Ind Med 1998; 34: 15-19. http.dx.doi.org/10.1002/(SICl)10970274(199807)34:1<15::AID-AJIM3 >3.0.CO;2-P

38. Stone PW, Clarke SP, Cimiotti J, Correa-de-Araujo R. Nurses' working conditions: Implications for infectious disease. Emerging Infec Dis 2004; 10(11): 1984-1988.

39. de Vries B, Cossart YE. Needlestick injury in medical students. Med J Aust 1994; 160: 398-400.

40. Hanrahan A, Reutter L. A critical review of the literature on sharps injuries: epidemiology, management of exposures and prevention. J Advanc Nursing 1997; 5: 144-54. http. dx.doi.org/10.1046/j.1365-2648.1997.1997025144.x

41. Gerberding JL. Management of occupation exposures to blood borne viruses. N Engl J Med 1995; 332: 444-451. http. dx.doi.org/10.1056/NEJM199502163320707

42. Manian FA. Hepatitis $C$ after needle stick injuries. Ann Intern Med 1992; 116: 345-346.

43. Puro V, Petrosilla N, Ippolito G. Italian study group on occupation Risk of HIV and other Blood-borne Infections. Risks of hepatitis $C$ seroconversion after occupational exposure in health care workers. Am J Infect Control 1995; 23: 273-277. http.dx.doi.org/10.1016/0196-6553(95)90056-X

44. Gerberding JL. Incidence and prevalence of human immunodeficiency virus, hepatitis B virus, hepatitis $C$ virus and cytomegalovirus among health car personnel at a risk of blood exposure: a final report from a longitudinal study. J Infect Dis 1994; 170: 1410-1417. http.dx.doi.org/10.1093/ infdis/170.6.1410

45. Cuny E, Fredekind RE, Budenz AW. Dental safety needles' effectiveness: results of a one-year evaluation. I Am Dent Assoc 2000; 131: 1443-1448.

46. Trim JC. A review of needle-protective devices to prevent sharps injuries. Br J Nursing 2004; 13: 146-153.

47. Tereskerz PM. Legal implications of needlestick injuries. J Intravenous Nursing 1997; 20(6 Suppl): S25-32. 